\title{
Understanding Differential Responses of Grapevine (Vitis vinifera L.) Leaf and Fruit to Water Stress and Recovery Following Re-Watering
}

\author{
Bhaskar Bondada*, Janani Shutthanandan \\ Washington State University Tri-Cities, Richland, USA. \\ Email: bbondada@wsu.edu \\ Received July $4^{\text {th }}, 2012$; revised July $31^{\text {st }}, 2012$; accepted August $10^{\text {th }}, 2012$
}

\begin{abstract}
Among all fruit crops of horticultural importance, grapevines (Vitis vinifera L.) stand out as the most drought tolerant crop species whose tolerance is credited to their proficiency to recover from water stress in both the natural and vineyard growing conditions. However, information on the recovery responses is relatively scant. Studies were conducted to address this issue using potted vines of the grapevine cultivar, Cabernet Sauvignon, which was subjected to water stress and along with anatomical and ultrastructural characterizations, physiological status was assessed in healthy and water stressed vines, and following recovery via rewatering from the water stressed vines. Water stress induced wilting of leaves, drooping of tendrils, and desiccation followed by abscission of shoot tip leaving behind a brown scar at the shoot apex. The wilted leaves accumulated ABA, which correspondingly reduced stomatal conductance and leaf water potential. Upon re-watering, both these parameters made a recovery with values similar to healthy leaves. Likewise, leaf anatomical features following rewatering resembled to that of healthy leaves. In clusters, water stress caused shriveling of preveraison (unripened) berries, which regained full turgor following water resupply, whereas the postveraison (ripening) berries in the same cluster remained unaffected as evidenced by the presence of viable mesocarp cells and epicuticular wax in the form of platelets. The study revealed that shoot tip with leaf primordia was most sensitive to water stress followed by fully expanded leaves and preveraison berries, whereas the postveraison berries remained unaffected. This information could be valuable to implementing irrigation strategies towards sustaining grape production in existing vineyards experiencing episodic droughts and targeted areas prone to drought.
\end{abstract}

Keywords: ABA; Berry; Leaf Water Potential; Water Stress; Vitis vinifera

\section{Introduction}

Horticultural crops of commercial importance grown as non-irrigated crop in temperate and as an irrigated crop in semi-arid climates recurrently encounter drought periods due to either inadequate rainfall or a lack of irrigation frequency. Because among all abiotic factors, drought elicits substantial changes in plant metabolism, it has become a custom to specify the destructive effects of drought by examining the physiological and anatomical responses of plants to varied levels of water stress and desiccation [1-4]. However, equally important is gaining an insight into the efficacy and the underlying mechanisms involved in recovery from water stress following water resumption. This premise has ignited an increasing interest in exploring the recovery responses of water stressed plants following watering events. For instance, in recent years, several studies have examined the reco-

\footnotetext{
"Corresponding author.
}

very responses after a water stress event for a wide range of plants including annuals $[5,6]$ and perennials $[7,8]$. While there exists plethora of information on drought induced changes in grapevine (Vitis vinifera) development and function [4,9-10], not much is known about recovery responses from water stress, especially in own-rooted vines, which serve as the propagatory material for establishing vineyards in many parts of the world. This is crucial information as the capacity to overcome and recover from water stress after rainfall or irrigation would aid in ascertaining adaptive features for planting grapevines in areas facing severe drought conditions. Having made that remark, it must be emphasized that there exist a few studies pertaining to recovery responses of water-stressed grapevines; however, these studies primarily dealt with rootstocks showing increases in its water use efficiency (WUE) after a period of water deficit [11], but upon grafting, the grafted vines failed to show similar response [12]. 
As opposed to other fruit crops, grapevine is unique in that it is among the most ancient and widely cultivated fruit crops grown both as a non-irrigated crop in temperate and an irrigated crop in semi-arid climates worldwide wherein it encounters continuous cycles of water stress and re-watering either via rainfall or irrigation. Hence, the need for studies focusing on the recovery responses of water stressed grapevines is well justified especially in view of the recent trends and most climate models that project summer drought conditions to be aggravated in the foreseeable future by increasing the severity as well as the frequency of severe droughts [13]. In such situations, an understanding of recovery responses of waterstressed grapevines can play a major role in maximizing growth and production eventually leading to sustainability of grape production. Furthermore, given the availability of the grapevine genome sequence [14] and the fact that grapevine is used as a model plant to study ecophysiological responses to water stress, the information garnered from this study will be crucial not only to grape production but also to better managing and sustaining other perennial fruit crops under droughted conditions. Therefore, the objective of this study was to gain an understanding of grapevine's recovery by characterizing morpho-anatomical and physiological responses of leaves and clusters to water stress.

\section{Materials and Methods}

\subsection{Plant Material}

We used two-year old own rooted potted vines of Cabernet Sauvignon propagated using cuttings acquired from Inland Desert Nursery Inc. (Benton City, WA, USA) for our experiment (2006 and 2007). The vines were grown in $20 \mathrm{~L} \mathrm{PVC}$ pots containing a mixture of $50 \%$ sandy loam, $25 \%$ peat moss, $25 \%$ pumice and $30 \mathrm{~g} / \mathrm{L}$ dolomite. The bulk density of these mixtures was $\sim 1$ $\mathrm{g} \cdot \mathrm{cm}^{-3}$. Volumetric water content at field capacity was $\sim 34 \%$. The vines were grown outside at Richland, WA $\left(46^{\circ} 28^{\prime} \mathrm{N} ; 119^{\circ} 28^{\prime} \mathrm{W}\right.$; elevation $\left.120 \mathrm{~m}\right)$.

A Hydrosense soil water sensor (Campbell Scientific Inc., North Logan, Utah, USA) was used to control soil moisture. During early season (before water stress treatment), vines were irrigated completely i.e. until water exuded from the pores on the pot's bottom in which case the soil moister was around $30 \%$ corresponding to field capacity $(\sim 34 \%)$. This amount of water was used to compose $100 \%$ irrigation treatment (control), which equated to 3 liters of water per pot per day and the water stress treatment received $33 \%$ of the control (1 liter per pot per day with a soil moisture of around $7 \%-10 \%$ ). Pots were irrigated by manually watering mid-morning to achieve the target water content. The stress treatment was initiated prior to veraison when ripening commences in grape berries.

\subsection{Stomatal Conductance}

Single leaf measurements were taken using a leaf porometer (SC-1, Decagon Devices, Pullman, WA). Fully expanded sun exposed leaves were selected to make measurements between 10 am and noon.

\subsection{Leaf Water Potential ( $\Psi)$}

A portable pressure chamber (PMS Instruments, Albany, OR) was used to estimate mid-day $\Psi$ according to Williams and Araujo (2002) [15].

\subsection{ABA Analysis}

ABA concentrations in the leaves were measured with the Phytodetek ABA enzyme immunoassay test kit (Agdia Inc., Elkhart, IN) following manufacturer's instructions.

\subsection{Light Microscopy}

To examine the internal morphological features of leaves and berries, small tissue samples were cut using a razor blade; subsequently, the tissues were fixed and preserved in formalin-acetic acid-alcohol. The fixed tissues were dehydrated using the tertiary butyl alcohol series, infiltrated and embedded in paraffin, sectioned at $\approx 10 \mu \mathrm{m}$ with a microtome (MT 990; Boeckeler Instruments, Tucson, AZ), affixed to glass slides $(8 \times 3 \mathrm{~cm})$, and stained with the Toluidine blue (1\%) and Johansen's safranin $[1 \%(\mathrm{w} / \mathrm{v})$ dissolved in $50 \%$ ethanol] and fast green $[0.2 \%(\mathrm{w} / \mathrm{v})$ dissolved in $95 \%$ ethanol] protocol [16]. The staining procedure involved rehydration in descending strengths of alcohol, staining with safranin, dehydration in ascending strengths of alcohol, and counterstaining with fast green. When staining was complete, a drop of Permount mounting medium (Fisher Scientific, Fair Lawn, NJ) was used to affix coverslips to the slides. Slides were placed under a compound microscope (Axioskop 2 plus; Carl Zeiss, Thornwood, NY) attached with a digital camera (DXM 1200C; Nikon Instruments, Melville, NY), which was used for capturing digital images.

\subsection{Cell Viability (Membrane Integrity)}

Cell viability was assessed first by staining cut surfaces of berries with 5,(6)-Carboxyfluorescein Diacetate (5,6CFDA SE) and then observing stained berries with confocal laser scanning microscopy (CLSM). Stock CFDA was made up as follows: $1 \mathrm{ml}$ of dimethyl sulphoxide (DMSO) was added to $100 \mathrm{mg}$ of 5,6-CFDA (Invitrogen, Carlsbad, CA, USA). Thereafter, 1 - $2 \mu$ l of the stock was 
added to polypropylene vials containing $1 \mathrm{ml}$ distilled water. Stock and working strength 5,6-CFDA were kept foil-wrapped and stored at $-4^{\circ} \mathrm{C}$ until needed. Healthy and berry shrivel berries were cut longitudinally through the median into two equal halves, and each half was stained with CFDA solution for $15 \mathrm{~min}$.

A Zeiss Confocal microscope (LSM 510 Meta Laser Scanning Microsope, Carl Zeiss Inc., Thornwood, NY, USA) was used to image fluorescence as quickly as possible to minimize the dye loss. The fluorescence of CFDA was analyzed by excitation at $488 \mathrm{~nm}$, and emission was detected at bandpath of $505-570 \mathrm{~nm}$. The fluorescence of cells was captured using a digital camera.

All quantitative data were analyzed by one-way ANOVA using SPSS (SPSS Statistical Package 11; SPSS, Chicago, IL, USA).

\section{Results and Discussion}

\subsection{Water Stress Effects on Vegetative Structures}

\section{Shoot Morphology, ABA, and Leaf Physiology}

It is well known that plants experiencing water stress undergo morphological and physiological changes. For instance, Schultz and Matthews (1988) [17] showed that the hydraulic conductivity of grapevine shoot diminished when the soil water was depleted. Our study provided a morpho-physiological manifestation of such hydraulic challenge in the form of dehydrated shoot apex followed by its abscission leaving behind a brown scar at the distal end of the stem (Figure 1(a)). The leaves of the same shoot exhibited a wilted appearance while the tendrils first drooped, then desiccated and finally turned brown (Figure 1). In contrast, the well irrigated shoot system had turgid leaves and upward growing tendrils that outgrew the shoot tip (Figure 1(b)) organized with several leaf primordia and a young bifuricated tendril with hydathodes at their tips (Figure 1(c)). The particular sequence in which these organs exhibited wilting in water stressed shoot was not recorded but it generally first starts with tendrils, then summer laterals followed by main leaves [18]; however, the sensitivity to growth does not differ among these organs during their ontogeny [19]. These adverse indices are typical expression of grapevines exposed to water stress conditions. In plants displaying such symptoms, it is common to interpret them in terms of a fall in leaf turgor and water potential, which arises from the roots failing to extract water quickly enough from the drying soil [20]. Accordingly, water stress activates removal of water from the cytoplasm to the extracellular space causing a reduction in the cytosolic and vacuolar volumes, hence the wilted appearance of the grapevine shoot system. Concomitant with these mo-

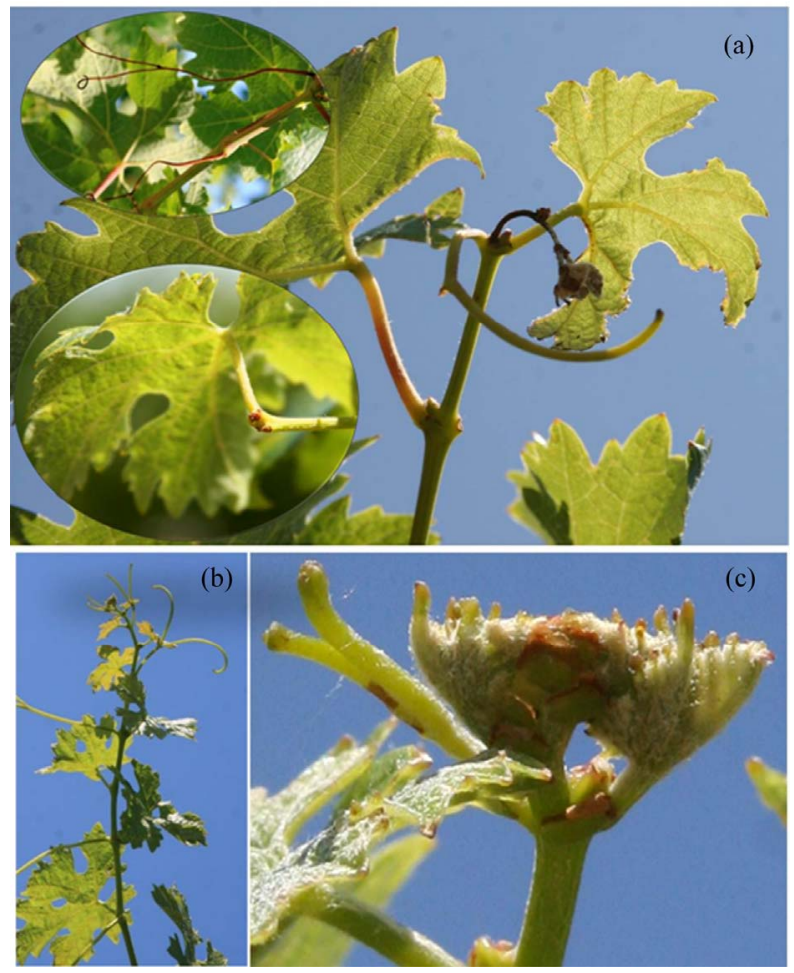

Figure 1. Photographs of (a) a water-stressed Cabernet Sauvignon shoot with desiccated and drooping apex, desiccated and brown tendrils (upper inset) and the shoot apex with a brown scar following the abscission of the apex (lower inset); (b) a well irrigated Cabernet Sauvignon shoot system showing turgid leaves and upward growing tendrils that outgrew the shoot tip; and (c) a close up of shoot tip from B showing several leaf primordia and a young bifuricated tendril with hydathodes at their tips.

difications, biochemical changes ensued in the form of ABA (abscisic acid) accumulation (Figure 2) occurring most probably in the petiole xylem and leaf $[21,22]$. Such response is a highly accepted testament to plants experiencing water stress as this phytohormone serves as the predominant chemical message in plants experiencing water stress [23]. It is well known that whenever ABA accumulates, stomatal conductance de- clines as evidenced by correlations between stomatal conductance and the ABA from both xylem and leaf tissues [24]. This explains the low stomatal conductance of water-stressed leaves (Figure 3), which most plausibly also endured a reduction in the hydraulic conductivity of its vascular system as a decline in stomatal conductance due to constrained stomatal aperture [4] parallels with reduced hydraulic conductivity [25]. The limited stoma- tal conductance has been considered to be an immediate response of grapevines to water stress originating either from partial root drying [26] or to soil water deficits on both a diurnal and seasonal basis [27]. Thus, it is quite evident that a reduction in stomatal conductance is the first 


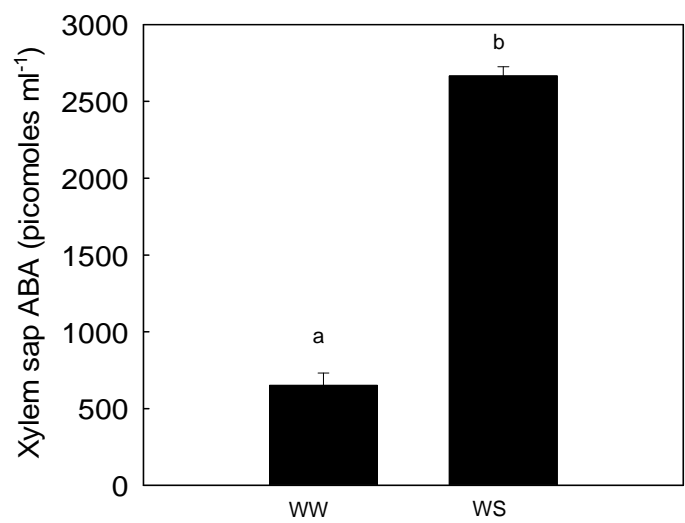

Figure 2. Changes in ABA accumulation in leaves of well watered and water-stressed Cabernet Sauvignon (WW: well water; WS: water stress). Bars (Mean \pm SE) sharing a common letter are not significantly different $(P<0.05)$.
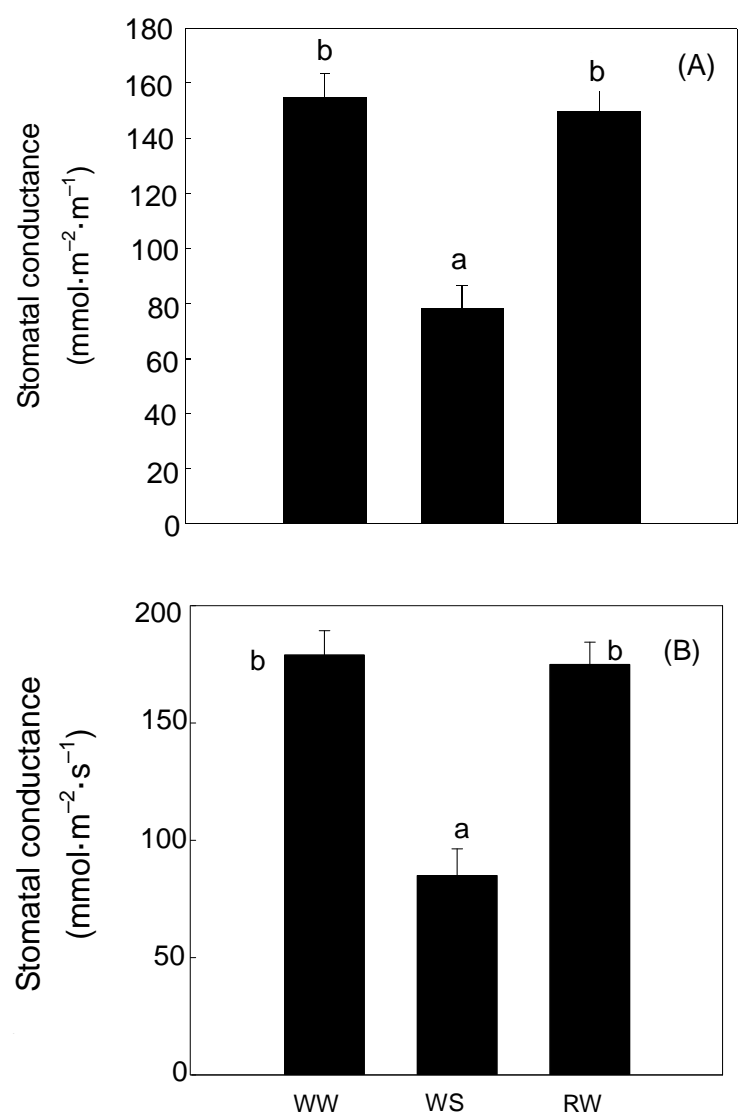

Figure 3. Changes in stomatal conductance as influenced by water stress and recovery following rewatering in Cabernet Sauvignon in (A) 2006 and (B) 2007. (WW: well water; WS: water stress; RW: rewatering).

physiological consequence of roots deprived of water.

As is well known that both leaves and roots synthesize ABA under water stress conditions $[11,22]$ and the fact we did not perform separate ABA analysis for roots and leaves, implicit in our study was the uncertainty about the source of ABA. However, based on the observations made so far in grapevines dealing with water stress, (Lovisolo et al., 2010) [4] posited that root ABA synthesis most likely in the vascular parenchyma cells [28] transported through the xylem into leaves as conjugate forms [29] facilitates most of the stomatal response. This is in contrast to the model plant, Arabidopsis whose stomatal conductance response to soil water stress is due to increased ABA synthesis in the shoots, not in the roots [30].

Since stomata are the major control point for plant water relations controlling water loss and gas exchange [31], the decline in stomatal conductance unequivocally implied that the steepest gradient in the soil-vine-atmosphere continuum occurred at the leaf surface. In such a situation, the leaf water potential is expected to be unchanged. However, this did not occur in the water stressed leaves (Figure 4), so it was possible that the reduced leaf water status influenced stomatal conductance either directly or by inducing ABA accumulation. Support for this contention can be derived from grafting experiments entailing wild type and ABA-deficient tomato mutants [32]. They found that stomatal closure in response to root drying was rather associated with transmission of some signal, for example, a precursor other than $\mathrm{ABA}$ from the roots. While examining the stomatal response of different grapevine cultivars to VPD, Soar et al. (2006) [33] speculated that such a precursor could trigger aquaporin operation leading to a change in hydraulic properties, which is likely to reduce leaf water potential and stomatal conductance concurrently. Hence it appears that in addition to ABA metabolism, hydraulic signals (cavitation), and expression and activity of aquaporins [4], drought-induced stomatal closure is linked to changes in leaf water status measured as leaf water potential.

\subsection{Recovery of Vegetative Structures}

Leaf Morphological and Physiological Features

Upon re-watering, the leaves recovered fully as indicated by their anatomical (Figure 5(A)) and physiological responses (Figures 3 and 4). For instance, physiologically, the stomatal conductance and leaf water potential (Figures 3 and 4) were almost similar to and the anatomical details resembled to that of fully watered leaves (Figure 5(A)) whose detailed structures have been well described in recent studies [34,35]. This will restore photosynthetic function, which generally declines during water stress [36], due to its strong correlation with stomatal conductance [37]. While at a molecular level, recovery from water stress elicits complex transcriptomic responses in grapevine [38]. Similar to our study, Chaves and Rodri- 

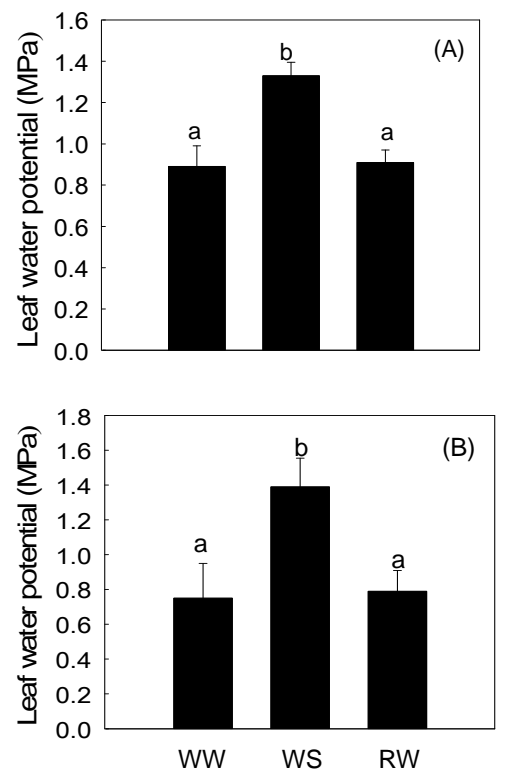

Figure 4. Changes in midday leaf water potential as influenced by water stress and recovery following rewatering in Cabernet Sauvignon in (A) 2006 and (B) 2007 (WW: well water; WS: water stress; $R W$ : rewatering).

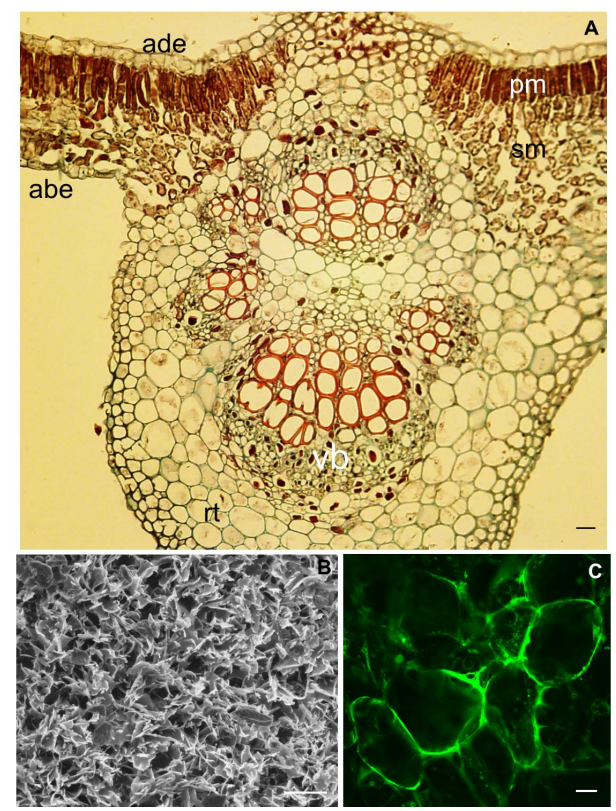

Figure 5. Transverse light micrograph of a (A) well-irrigated leaf showing adaxial epidermis, abaxial epidermis, palisade parenchyma cells, and spongy mesophyll cells, several vascular bundles and rib tissues; (B) scanning electron micrograph of berry surface showing fine, loose, shiny, and off-white aggregates of epicuticular wax platelets and (C) a confocal laser scanning micrograph of mesocarp showing green fluorescence as thin oblong illumination from the parenchyma cells. Scale bars: $20 \mu \mathrm{m}$ (A); $1.25 \mu \mathrm{m}$ (B); $50 \mu \mathrm{m}$ (C). ade: adaxial epidermis; abe: abaxial epidermis; pm: palisade mesophyll; sm: spongy mesophyll; vb: vascular bundle; rt: rib tissues. gues (1987) [39] reported full recovery after re-watering the stressed vines that exhibited minimum leaf water potential of -2.2 to $-3 \mathrm{MPa}$. These observations indicated that re-watering reversed the effects of water stress on leaf physiology enabling the vines to survive much stronger water stress conditions. On the contrary, the decreased leaf water potential of apical shoot xylem in maize did not recover even during extended periods of no transpiration [40]. In a similar context, although water stressed lemon plant (Citrus lemon) recovered leaf water potential fully, the stomatal conductance did not make a recovery [41]. Bases on these observations, it is reasonable to suggest that compared to other crops, grapevines are lot more elastic in their capacity to cope up with water stress.

The mechanistic basis of recovery from water stress is not clear from our study, yet we propose that the water stress induced ABA accumulation in addition to causing reductions in stomatal conductance facilitated growth resumption following re-watering in both leaves as well as berries. This conjecture is based on its role in recovery process observed in other crops. For instance, ABA triggered leaf growth in water-stressed maize by impeding overload of the growth-inhibitory hormone ethylene [42]. With respect to grapevine, Perrone et al. (2011) [38] contended that $\mathrm{ABA}$ also aids in the recovery of water stressed grapevines. Although this could be possible by increasing solute transport [43] and photosynthetic import [44] towards growing cells or by stimulating hydraulic conductivity [45], their argument was based on the different patterns of $\mathrm{ABA}$ accumulation in recovering vines under different levels of transpiration $[36,46]$.

\subsection{Effect of Water Stress on Berries}

\subsubsection{Pre-Veraison Berries}

In the cluster, the pre-veraison (un-ripened) berries responded to water stress by wrinkling their exocarp (Figure 6). As has been previously reported [47-49] and the fact that girdled clusters develop shriveled berries [50], such behavior was indicative of un-ripened (preveraison) berries receiving saps from both xylemic (predominantly) and phloemic pathways from the vine not only under well watered conditions but also during water stress conditions. Furthermore, it can be said that as grapevines experience water stress, first the leaf water potential declines (Figure 4), which in turn triggers water efflux mechanism primarily for backflow into the vine in an attempt to maintain stomatal conductance and leaf water potential. However, despite stomatal closure, the leaf water potential was not maintained (Figure 4). This was not surprising since pre-veraison berries are known to transpire water [48,51], which would downsize the pool of water intended for backflow into the vine. From these 


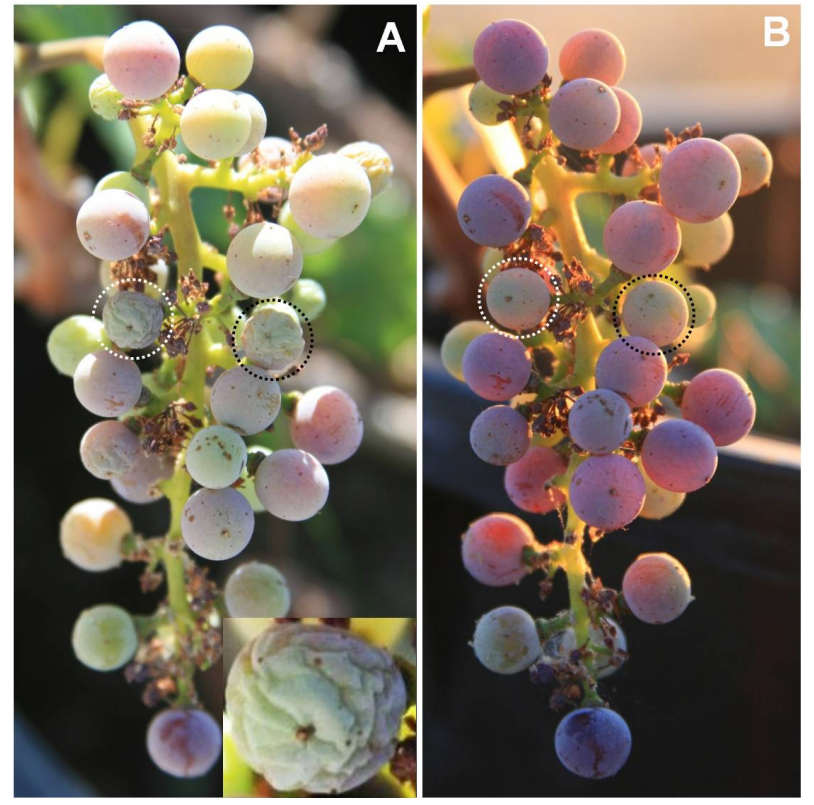

Figure 6. Photographs of (A) water-stressed cluster showing shriveling of primarily preveraison (unripened) berries (encircled) and (B) same cluster showing full expansion of previously shriveled berries (encircled) following irrigation.

responses, it is evident that leaves are more sensitive to water stress than berries. Nevertheless, insufficient water supply during berry cell division and cell expansion will inhibit berry size causing large and significant changes in the metabolism and composition [52]. Although water stress significantly reduced the volume and modified the global structure of the berry affecting the macroscopic characteristics, the wax morphology was unaltered (Figure 5(B)). Whether or not the berries underwent quantitative and qualitative changes in wax composition is not clear from this study; however, plant fruiting organs are known to dramatically change their wax composition to withstand water stress [53].

\subsubsection{Post-Veraison Berries}

On the contrary, the post-veraison berries i.e. berries that started to accumulate anthocyanins, in the same cluster (Figure 6) did not deform and maintained integrity of their pericarp as revealed by their viable cells and epicuticular wax in the form of platelets (Figure 5(B)). Based on the findings by Keller et al. (2006), it is logical to infer that even under water stress conditions, phloem influx alone was suffice to cause the second phase of berry expansion and that the xylem influx was unnecessary even though a structurally intact xylemic pathway is always available for use [49,57]. Consequently, the berries were spherical (Figure 6(B)) caused by turgid mesocarp cells with semipermeable plasmalemma and a very low osmotic potential as evidenced by a thin fluorescence emitting from their cytoplasm (Figure 5(C)). A low osmotic potential of the mesocarp cells is expected to balance the negative pressure in the apoplast and the tension generated in vine xylem by leaf transpiration allowing high hydraulic conductance to the vine [58]. This crafts an ideal setting for backflow to occur especially in the event of water stress [49] causing shriveling of berries as observed with un-ripened (no or less color) berries, not with ripened berries of the present study. This indicated that despite the reversal of xylem flow during veraison [49], the ripening berries are relatively less sensitive to water stress. A similar conclusion was made by Creasy and Lombard (1993) [59] who reported that berry growth rate and deformability were much more sensitive to vine water stress before veraison than after. This type of behavior can be interpreted as stimulating phloem unloading while preventing fruits from undergoing diurnal fluctuations of water potential [60]. On the other hand, if the water deficit prolonged, then the ripening berries will certainly shrivel via dehydration as in that case the xylem efflux plus berry transpiration will exceed phloem influx [49]. Another scenario for grape berries to shrivel include when berries develop various physiological disorders associated with ripening [61-63]. Many of these disorders are characterized by cell death rendering the cell membranes non selective $[62,64]$.

\subsection{Recovery Following Re-Watering}

\section{Pre-Veraison Berries}

Upon re-watering, the preveraison berries fully recovered (Figure 6) analogous to leaves. Thus, it appeared that re-watering reversed the gradients of water potential and reestablished the hydraulic conductivities of the water pathway from vine to berry cells. Such conditions will restore expansive growth as shown by these un-ripened berries by generating turgor pressure via water entry into cells. Hence, the recovery following watering was a clear evidence of water loss occurring from the vacuolar compartment of the parenchymatous mesocarp cells during water stress with minor changes in the water content of both the cytoplasm and the cell wall compartments. On the other hand, the color development following recovery had less to do with both water stress effect and the recovery process even though water deficits accelerate ripening and induce changes in gene expression regulating flavonoid biosynthesis in grape berries [54]. Instead, since the vines were stressed before veraison, the post recovery period happened to coincide with ripening phase and thereafter the recovered berries appeared to be unaffected by water stress (Figure 6). The water stress induced shriveling and recovery of un-ripened berries is comparable to diurnal and seasonal transpiration and shriveling of fruits including grapes that use this rhythm- 
mic cycle to lower fruit water potential for enhancing vascular import into the fruit $[55,56]$.

To conclude, this study demonstrated that the shoot tip with leaf primordia was most sensitive to water stress followed by fully expanded leaves and pre-veraison berries, whereas the post-veraison berries remained unaffected. Following watering, the stressed organs and fruits regained full growth. Thus it appears that by taking the sensitivity of vine organs into consideration, increased irrigation efficiency is possible in areas with water shortage.

\section{REFERENCES}

[1] N. D. Hallam and S. E. Luff, "Fine Ultrastructural Changes in the Mesophyll Tissues in the Leaves of the Xerophyta Villosa during Desiccation," Botanical Gazette, Vol. 141, No. 2, 1980, pp. 173-179. doi:10.1086/337140

[2] K. Chartzoulakisa, A. Patakasb, G. Kofidisc, A. Bosabalidisc and A. Nastou, "Water Stress Affects Leaf Anatomy, Gas Exchange, Water Relations and Growth of Two Avocado Cultivars," Scientia Horticulturae, Vol. 95, No. 1-2, 2002, pp. 39-50. doi:10.1016/S0304-4238(02)00016-X

[3] H. R. Schultz and M. Stoll, "Some Critical Issues in Environmental Physiology of Grapevines: Future Challenges and Current Limitations," Australian Journal of Grape and Wine Research, Vol. 16, No. s1, 2010, pp. 4-24. doi:10.1111/j.1755-0238.2009.00074.x

[4] C. Lovisolo, I. Perrone, A. Carra, A. Ferrandino, J. Flexas, H. Medrano and A. Schubert, "Drought-Induced Changes in Development and Function of Grapevine (Vitis spp.) Organs and in Their Hydraulic and Non-Hydraulic Interactions at the Whole-Plant Level: A Physiological and Molecular Update," Functional Plant Biology, Vol. 37, No. 2, 2010, pp. 98-116. doi:10.1071/FP09191

[5] G. H. Salekdeh, J. Siopongco, L. J. Wade and B. Ghareyazie, "John Bennettlproteomic Analysis of Rice Leaves during Drought Stress and Recovery," Proteomics, Vol. 2, No. 9, 2002, pp. 1131-1145. doi:10.1002/1615-9861(200209)2:9<1131::AID-PROT11 31>3.0.CO;2-1

[6] M. G. D. Dos Santos, R. V. Ribeiro, R. F. D. Oliveira, E. C. Machado and C. Pimentel, "The Role of Inorganic Phosphate on Photosynthesis Recovery of Common Bean after a Mild Water Deficit," Plant Sciences, Vol. 170, No. 3, 2006, pp. 659-674. doi:10.1016/j.plantsci.2005.10.020

[7] B. Dichio, C. Xiloyannis, A. Sofo and G. Montanaro, Osmotic Regulation in Leaves and Roots of Olive Trees during a Water Deficit and Rewatering," Tree Physiology, Vol. 26, No. 2, 2006, pp. 179-185. doi:10.1093/treephys/26.2.179

[8] A. Galle, P. Haldimann and U. Feller, "Photosynthetic Performance and Water Relations in Young Pubescent Oak (Quercus pubescens) Trees during Drought Stress and Recovery," New Phytologist, Vol. 174, No. 4, 2007, pp. 799-810. doi:10.1111/j.1469-8137.2007.02047.x

[9] L. E. Williams and M. A. Matthews, "Grapevine,” In: B. A. Stewart and D. R. Nielsen, Eds., Irrigation of Agricultural Crops, Agronomy Monograph No. 30, ASA-CSSASSSA, Madison, 1990, pp. 1019-1055.

[10] M. Keller, "Managing Grapevines to Optimise Fruit Development in a Challenging Environment: A Climate Change Primer for Viticulturists," Australian Journal of Grape and Wine Research, Vol. 16, No. s1, 2010, pp. 5669. doi:10.1111/j.1755-0238.2009.00077.x

[11] A. Pou, J. Flexas, M. D. Alsina, J. Bota, C. Carambula, F. de Herralde, J. Galmes, C. Lovisolo, M. Jimenez, M. Ribas-Carbo, D. Rusjan, F. Secchi, M. Tomas, Z. Zsofi and H. Medrano, "Adjustments of Water Use Efficiency by Stomatal Regulation during Drought and Recovery in the Drought-Adapted Vitis hybrid Richter-110 (V. berlandieri $\times$ V. rupestris)," Physiologia Plantarum, Vol. 134, No. 2, 2008, pp. 313-323. doi:10.1111/j.1399-3054.2008.01138.x

[12] M. Gomez-del-Campo, P. Baeza, C. Ruiz, V. Sotes and J. R. Lissarrague, "Effect of Previous Water Conditions on Vine Response to Rewatering," Vitis, Vol. 46, No. 2, 2007, pp. 51-55.

[13] F. Giorgi and P. Lionello, "Climate Change Projections for the Mediterranean Region," Global and Planetary Change, Vol. 63, No. 1-2, 2008, pp. 90-104. doi:10.1016/j.gloplacha.2007.09.005

[14] O. Jaillon, J. M. Aury, B. Noel, et al., "The Grapevine Genome Sequence Suggests Ancestral Hexaploidization in Major Angiosperm Phyla," Nature, Vol. 449, No. 7162, 2007, pp. 463-468. doi:10.1038/nature06148

[15] L. E. Williams and F. J. Araujo, "Correlations among Predawn Leaf, Midday Leaf, and Midday Stem Water Potential and Their Correlations with Other Measures of Soil and Plant Water Status in Vitis vinifera," Journal of the America Society for Horticultural Science, Vol. 127, No. 3, 2002, pp. 448-454.

[16] S. E. Ruzin, "Plant Microtechnique and Microscopy," Oxford University Press, New York, 1999.

[17] H. R. Schultz and M. A. Matthews, "Resistance to Water Transport in Shoots of Vitis vinifera L.: Relation to Growth at Low Water Potential," Plant Physiology, Vol. 88 , No. 3, 1988, pp. 718-724. doi: $10.1104 / \mathrm{pp} .88 .3 .718$

[18] E. T. Thorne, J. F. Stevenson, T. L. Rost, J. M. Labavitch and M. A. Matthews, "Pierce's Disease Symptoms: Comparison with Symptoms of Water Deficit and the Impact of Water Deficits," American Journal of Enology and Viticulture, Vol. 57, No. 1, 2006, pp. 1-11.

[19] H. R. Schultz and M. A. Matthews, "Vegetative Growth Distribution during Water Deficits in Vitis vinifera L," Australian Journal of Plant Physiology, Vol. 15, No. 5, 1988, pp. 641-656. doi:10.1071/PP9880641

[20] T. Gollan, J. B. Passioura and R. Munns, "Soil Water Status Affects the Stomatal Conductance of Fully Turgid Wheat and Sunflower Leaves," Australian Journal of Plant Physiology, Vol. 13, No. 4, 1986, pp. 459-464. doi:10.1071/PP9860459 
[21] B. R. Loveys, "Abscisic Acid Transport and Metabolism in Grapevine (Vitis vinifera L.)," New Phytologist, Vol. 98, No. 4, 1984, pp. 575-582. doi:10.1111/j.1469-8137.1984.tb04150.x

[22] M. L. Rodrigues, T. P. Santos, A. P. Rodrigues, C. R. de Souza, C. M. Lopes, J. P. Maroco, J. S. Pereira and M. M. Chaves, "Hydraulic and Chemical Signalling in the Regulation of Stomatal Conductance and Plant Water Use in Field Grapevines Growing under Deficit Irrigation," Functional Plant Biology, Vol. 35, No. 7, 2008, pp. 565579. doi:10.1071/FP08004

[23] I. C. Dodd, "Root-to-Shoot Signalling: Assessing the Roles of 'Up' in the Up and Down World of Long-Distance Signalling in Planta," Plant and Soil, Vol. 274, No. 1-2, 2005, pp. 251-270. doi:10.1007/s11104-004-0966-0

[24] C. Lovisolo, W. Hartung and A. Schubert, "Whole-Plant Hydraulic Conductance and Root-to-Shoot Flow of Abscisic Acid Are Independently Affected by Water Stress in Grapevines," Functional Plant Biology, Vol. 29, No. 11, 2002, pp. 1349-1356. doi:10.1071/FP02079

[25] A. S. Cohen, Z. Attia and M. Moshelion, "Bundle-Sheath Cell Regulation of Xylem-Mesophyll Water Transport via Aquaporins under Drought Stress: A Target of XylemBorne ABA?" The Plant Journal, Vol. 67, No. 1, 2011, pp. 72-80. doi:10.1111/j.1365-313X.2011.04576.x

[26] P. R. Dry and B. R. Loveys, "Grapevine shoot Growth and Stomatal Conductance Are Reduced When Part of the Roots are Dried," Vitis, Vol. 38, No. 4, 1999, pp. 151156.

[27] L. E. Williams, N. K. Dokoozlian and R. Wample, "Grape," In: B. Schaffer and P. C. Anderson, Eds., Handbook of Environmental Physiology of Fruit Crops, CRC Press, Boca Raton, 1994, pp. 85-133.

[28] A. Endo, Y. Sawada, H. Takahashi, M. Okamoto, K. Ikegami, H. Koiwai, M. Seo, T. Toyomasu, W. Mitsuhashi, K. Shinozaki, M. Nakazono, Y. Kamiya, et al., "Drought Induction of Arabidopsis 9-Cis-Epoxycarotenoid Dioxygenase Occurs in Vascular Parenchyma Cells," Plant Physiology, Vol. 147, No. 4, 2008, pp. 1984-1993. doi:10.1104/pp.108.116632

[29] R. Munns and R. E. Sharp, "Involvement of Abscisic Acid in Controlling Plant Growth in Soils of Low Water Potential," Australian Journal of Plant Physiology, Vol. 20, No. 5, 1993, pp. 425-437. doi:10.1071/PP9930425

[30] A. Christmann, E. W. Weiler, E. Steudle and E Grill, "A Hydraulic Signal in Root-to-Shoot Signalling of Water Shortage," The Plant Journal, Vol. 52, No. 1, 2007, pp. 167-174. doi:10.1111/j.1365-313X.2007.03234.x

[31] H. Lambers, F. S. Chapin and T. L. Pons, "Plant Physiological Ecology," Springer-Verlag, New York, 2008. doi:10.1007/978-0-387-78341-3

[32] N. M. Holbrook, V. R. Shashidar, R. A. James and R. Munns, "Stomatal Control in Tomato with ABA-Deficient Roots: Response of Grafted Plants to Soil Drying," Journal of Experimental Botany, Vol. 53, No. 373, 2002, pp. 1503-1514. doi:10.1093/jexbot/53.373.1503

[33] C. J. Soar, J. Speirs, S. M. Maffei, A. B. Penrose, M. G.
McCarthy and B. R. Loveys, "Grape Vine Varieties Shiraz and Grenache Differ in Their Stomatal Response to VPD: Apparent Links with ABA Physiology and Gene Expression in Leaf Tissue," Australian Journal of Grape and Wine Research, Vol. 12, No. 1, 2006, pp. 2-12. doi:10.1111/j.1755-0238.2006.tb00038.x

[34] B. Bondada, "Anomalies in Structure, Growth Characteristics, and Nutritional Composition as Induced by 2, 4-D Drift Phytotoxicity in Grapevine (Vitis vinifera L.) Leaves and Clusters," Journal of the American Society for Horticultural Science, Vol. 136, No. 3, 2011, pp. 165-176.

[35] B. Bondada, "Micromorpho-Anatomical Examination of 2, 4-D Phytotoxicity in Grapevine (Vitis vinifera L.) Leaves," Journal of Plant Growth Regulation, Vol. 30, No. 2, 2011, pp. 185-198. doi:10.1007/s00344-010-9183-7

[36] J. Flexas, M. Baron, J. Bota, J. M. Ducruet, A. Galle, J. Galmes, M. Jimenez, A. Pou, M. Ribas-Carbo, C. Sajnani, M. Tomas and H. Medrano, "Photosynthesis Limitations during Water Stress Acclimation and Recovery in the Drought-Adapted Vitis Hybrid Richter-110 (V. berlandieri $\times$ V. rupestris), , Journal of Experimental Botany, Vol. 60, No. 8, 2009, pp. 2361-2377. doi:10.1093/jxb/erp069

[37] S. C. Wong, I. R. Cowan and G. D. Farquhar, "Stomatal Conductance Correlates with Photosynthetic Capacity," Nature, Vol. 282, 1979, pp. 424-426. doi: $10.1038 / 282424 \mathrm{a} 0$

[38] I. Perrone, C. Pagliarani, C., Lovisolo, W. Chitarra, F. Roman and A. Schubert, "Recovery from Water Stress Affects Grape Leaf Petiole Transcriptome," Planta, Vol. 235, 2012, pp. 1383-1396. doi:10.1007/s00425-011-1581-y

[39] M. M. Chaves and M. L. Rodrigues, "Photosynthesis and Water Relations of Grapevines Growing in Portugal. Response to Environmental Factors," In: J. D. Tenhunen, et al., Eds., Plant Response to Stress. Functional Analysis in Mediterranean Ecosystems, NATO AS1 Series G, Springer Verlag, Berlin, Vol. 15, 1987, pp. 379-90.

[40] M. E. Westgate and J. S. Boyer, "Osmotic Adjustment and Inhibition of Leaf, Root, Stem, and Silk Growth at low Water Potentials in Maize," Planta, Vol. 164, No. 4, 1985, pp. 540-549. doi:10.1007/BF00395973

[41] M. C. Ruiz-Sanchez, R. Domingo, R. Save, C. Biel and A. Torrecillas, "Effect of Water Stress and Rewatering on Leaf Water Relations of Lemon Plants," Biologia Plantarum, Vol. 39, No. 4, 1997, pp. 623-631. doi:10.1023/A:1000943218256

[42] R. E. Sharp and M. E. Lenoble, "ABA, Ethylene and the Control of Shoot and Root Growth under Water Stress," Journal of Experimental Botany, Vol. 53, No. 366, 2002, pp. 33-37. doi:10.1093/jexbot/53.366.33

[43] S. K. Roberts and B. N. Snowman, "The Effects of ABA on Channel Mediated $\mathrm{K}^{+}$Transport across Higher Plant Roots," Journal of Experimental Botany, Vol. 51, No. 350, 2000, pp. 1585-1594. doi:10.1093/jexbot/51.350.1585

[44] H. Jones, R. A. Leigh, A. D. Tomos and R. G. Wyn Jones, 
"The Effect of Abscisic Acid on Cell Turgor Pressures, Solute Content and Growth of Wheat Roots," Planta, Vol 170, No. 2, 1987, pp. 257-262. doi:10.1007/BF00397896

[45] B. Parent, C. Hachez, E. Redondo, T. Simonneau, F. Chaumont and F. Tardieu, "Drought and Abscisic Acid Effects on Aquaporin Content Translate into Changes in Hydraulic Conductivity and Leaf Growth Rate: A Trans-Scale Approach," Plant Physiology, Vol. 149, No. 4, 2009, pp. 2000-2012. doi:10.1104/pp.108.130682

[46] C. Lovisolo, I. Perrone, W. Hartung and A. Schubert, "An Abscisic Acid-Related Reduced Transpiration Promotes Gradual Embolism Repair When Grapevines Are Rehydrated after Drought," New Phytologist, Vol. 180, No. 3, 2008, pp. 642-651. doi:10.1111/j.1469-8137.2008.02592.x

[47] M. A. Matthews and M. M. Anderson, "Fruit Ripening in Vitis vinifera L.: Responses to Seasonal Water Deficits," American Journal of Enology and Viticulture, Vol. 39, No. 4, 1988, pp. 313-320.

[48] M. D. Greenspan, H. R. Schultz and M. A. Matthews, "Field Evaluation of Water Transport in Grape Berries during Water Deficits," Physiologia Plantarum, Vol. 97, No. 1, 1996, pp. 55-62. doi:10.1111/j.1399-3054.1996.tb00478.x

[49] M. Keller, J. P. Smith and B. R. Bondada, "Ripening Grape Berries Remain Hydraulically Connected to the Shoot," Journal of Experimental Botany, Vol. 57, No. 11, 2006, pp. 2577-2587. doi:10.1093/jxb/erl020

[50] S. Rogiers, D. H. Greer, J. M. Hatfield, B. A. Orchards and M. Keller, "Solute Transport into Shiraz Berries during Development and Late-Ripening Shrinkage," American Journal of Enology and Viticulture, Vol. 57, No. 1, 2006, pp. 73-80.

[51] M. D. Greenspan, K. A. Shackel and M. A. Matthews, "Developmental Changes in the Diurnal Water Budget of the Grape Berry Exposed to Water Deficits," Plant, Cell and Environment, Vol. 17, No. 7, 1994, pp. 811-820. doi:10.1111/j.1365-3040.1994.tb00175.x

[52] G. Roby and M. A. Matthews, "Relative Proportions of Seed, Skin and Flesh, in Ripe Berries from Cabernet Sauvignon Grapevines Grown in a Vineyard Either Well Irrigated or under Water Deficit," Australian Journal of Grape and Wine Research, Vol. 10, No. 1, 2004, pp. 7482. doi:10.1111/j.1755-0238.2004.tb00009.x

[53] B. R. Bondada, D. M. Oosterhuis, J. B. Murphy and K. S. Kim, "Effect of Water Stress on the Epicuticular Wax Composition and Ultrastructure of Cotton (Gossypium hirsutum L.) Leaf, Bract, and Boil," Environmental and Experimental Botany, Vol. 36, No. 1, 1996, pp. 61-69. doi:10.1016/0098-8472(96)00128-1

[54] S. D. Castellarin, M. A. Matthews, G. Di Gaspero and G.
A. Gambetta, "Water Deficits Accelerate Ripening and Induce Changes in Gene Expression Regulating Flavonoid Biosynthesis in Grape Berries," Planta, Vol. 227, No. 1, 2007, pp. 101-112. doi:10.1007/s00425-007-0598-8

[55] H. G. Jones and K. H. Higgs, "Surface Conductance and Water Balance of Developing Apple (Malus pumila Mill.) Fruits," Journal of Experimental Botany, Vol. 33, No. 132, 1982, pp. 67-77. doi:10.1093/jxb/33.1.67

[56] L. M. McFadyen, R. J. Hutton and E. W. R. Barlow, "Effects of Crop Load in Fruit Water Relations and Fruit Growth in Peach," Journal of Horticultural Science, Vol 71, 1996, pp. 469-480.

[57] B. R. Bondada, M. A. Matthews and K. A. Shackel, "Functional Xylem Exists in Post Veraison Grape Berry," Journal of Experimental Botany, Vol. 56, No. 421, 2005 , pp. 2949-2957. doi:10.1093/jxb/eri291

[58] J. Tilbrook and S. D. Tyerman, "Cell Death in Grape Berries: Varietal Differences Linked to Xylem Pressure and Berry Weight Loss," Functional Plant Biology, Vol 35, No. 3, 2008, pp. 173-184. doi:10.1071/FP07278

[59] G. L. Creasy and P. B. Lombard, "Vine Water Stress and Peduncle Girdling Effects on Pre- and Post-Veraison Grape Berry Growth and Deformability," American Journal of Enology and Viticulture, Vol. 44, No. 2, 1993 pp. 193-197.

[60] W. Van Ieperen, V. S. Volkov and U. Van Meeteren, "Distribution of Xylem Hydraulic Resistance in Fruiting Truss of Tomato Influenced by Water Stress," Journal of Experimental Botany, Vol. 54, No. 381, 2003, pp. 317 324. doi:10.1093/jxb/erg010

[61] G. Hall, B. R. Bondada and M. Keller, "Loss of Rachis Cell Viability Is Associated with Ripening Disorders in Grapes," Journal of Experimental Botany, Vol. 62, No. 3, 2011, pp. 1145-1153. doi:10.1093/jxb/erq355

[62] B. R. Bondada and M. Keller, "Morpho-Anatomical Symptomatology and Osmotic Behavior of Grape Berry Shrivel," Journal of the American Society for Horticultural Science, Vol. 137, No. 1, 2012, pp. 20-30.

[63] B. R. Bondada and M. Keller, "Not All Shrivels Are Created Equal-Morpho-Anatomical and Compositional Characteristics Differ among Different Shrivel Types That Develop during Ripening of Grape (Vitis vinifera L.) Berries," American Journal of Plant Sciences, Vol. 3, 2012 (In Press). doi:10.4236/ajps.2012.37105

[64] M. Krasnow, M. A. Matthews and K. A. Shackel, "Evidence for Substantial Maintenance of Membrane Integrity and Cell Viability in Normally Developing Grape (Vitis vinifera L.) Berries throughout Development," Journal of Experimental Botany, Vol. 59, No. 4, 2008, pp. 849-859. doi:10.1093/jxb/erm372 